\title{
ROTAS DE FUGA DELEUZEANAS COMO ESTRATÉGIA DECOLONIAL NO ENSINO DE LÍNGUA ESPANHOLA NO BRASIL
}

\author{
Ana Caroline da Silva Santos ${ }^{1}$ \\ Lidyane Maria Ferreira de Souza ${ }^{2}$
}

\begin{abstract}
RESUMO
O ensino de Língua Espanhola é um dispositivo de conservação do domínio eurocêntrico estabelecido desde a colonização dos povos sul-americanos que segue silenciando e invisibilizando os saberes oriundos dos nativos dessas terras e dos africanos que foram violentamente trazidos a esse continente e, por imposição, passaram a ter o idioma espanhol como língua materna. Em diálogo com Sueli Carneiro (2005), Lélia Gonzalez (1988) e Sílvio Gallo (2003), apresentamos a racialidade e sua permanência nos discursos estabelecidos como verdades e no epistemicídio que até os dias atuais condena línguas, histórias e culturas de negros e indígenas à marginalidade. Através de reflexões a partir de alguns conceitos de Deleuze e Guattari, nos deslocamentos trazidos por Silvio Gallo, como rizoma e literatura menor, propomos trazer estes saberes silenciados para o ensino de Língua Espanhola no espaço escolar, em movimentos que possam contribuir para a decolonização no processo de ensino-aprendizagem. Novas perspectivas são lançadas sobre o ensino de línguas hispânicas para que haja uma educação formal que respeita e valoriza todas as culturas que fazem parte da nossa formação histórico-social para um devir - deleuzeano decolonial.
\end{abstract}

Palavras-chave: Decolonização. Deslocamentos. Ensino de Língua Espanhola. Eurocentrismo. Racialidade.

\section{ROUTES TRAIL DELEUZEANAS AS STRATEGY decolonial IN} LANGUAGE TEACHING SPANISH IN BRAZIL

\begin{abstract}
The Spanish Language teaching is a conservation device of the eurocentric domain estabilished since the colonization of the South American people and it still keeps silencing and ignoring the knowledge from the natives of this lands and africans who were violentily brought to this continent and, by imposition, adopted the Spanish idiom as their mother language. In dialogue with Sueli Carneiro (2005), Lélia Gonzalez (1988) and Gallo (2003), we present the raciality and its permanence in the discourse established as truth, and the epistemicide that remains until today, condemning the language, history and culture of black and indigenous maginalized. Through reflections about some Deleuze and Guattari's concepts, in the displacements brought by Silvio Gallo, as rhizome and minor literature, we propose to bring over these silenced knowledge to the Spanish Language teaching to school, establishing movements which can contribute with the teaching-learning decolonization process. New perspectives are launched on the hispanic language teaching for a formal education that respects and values all cultures that take part in our historical-social formation, for a become - decolonial deleuzean.
\end{abstract}

\footnotetext{
${ }^{1}$ Graduada em Letras com habilitação Língua Portuguesa/Língua Espanhola pela Universidade Estadual de Santa Cruz, especialista em Ensino de Língua Espanhola pela Universidade Cândido Mendes, mestranda em Ensino e Relações Étnico-raciais pela Universidade Federal do Sul da Bahia - Campus Sosígenes Costa e professora efetiva da rede pública estadual de ensino da Bahia. E-mail: ss.carol@hotmail.com

2 Professora adjunta no Instituto de Humanidades, Artes e Ciências, do Centro de Formação em Humanidades e no mestrado profissional em Ensino e Relações Étnico-raciais da Universidade Federal do Sul da Bahia - Campus Sosígenes Costa. Graduada em Ciências Jurídicas e Sociais pela Universidade Federal da Paraíba, Mestre em Ciências Jurídicas - Área de concentração em Direitos Humanos, por esta mesma Universidade. Doutora em Direitos Fundamentais no Mundo Global, pela Università di Camerino. E-mail: lidyane.ferreira@ufsb.edu.br
} 
Keywords: Decolonization. Displacements. Spanish Language Teaching. Eurocentrism. Raciality.

\title{
RUTAS DE ESCAPE DELEUZEANAS COMO UNA ESTRATEGIA DECOLONIAL EN LA EN LA ENSEÑANZA EN LENGUA ESPAÑOLA EN BRASIL
}

\begin{abstract}
RESUMEN
La enseñanza de la Lengua Española es un dispositivo de conservación del dominio ejercido por lo eurocentrismo colonial que fue establecido desde la colonización de los pueblos sur-americanos y sigue silenciando y invisibilizando los saberes venidos de los nativos de esas tierras y de los africanos que fueron violentamente traídos a eso continente y, por imposición, han tenido el idioma español como lengua materna. Estableciendo diálogos con Sueli Carneiro (2005), Lélia Gonzalez (1988) y Gallo (2003), presentamos la racialidad y su permanencia dentro de la sociedad a través de los discursos establecidos como verdad, como caminos para el epistemicídio que sigue hasta los días atuales condenando la lengua, historia y cultura de los negros e indígenas a la marginalidad. A través de reflexiones a partir de algunos conceptos de Deleuze y Guattari en los desplazamientos traídos por Silvio Gallo, como rizoma y literatura menor, son presentadas rutas de desplazamientos deleuzeanas para la enseñanza de la lengua española, proponiendo traer los saberes que fueron silenciados por siglos para el espacio escolar, instituyendo movimientos que puedan aportar para una decolonización en el proceso de enseño- aprendizaje. Nuevas perspectivas son lanzadas sobre el enseño de lenguas hispánicas para que haya una educación formal que respecta y valora todas las culturas que hacen parte de la nuestra formación histórico-social para uno devir-deleuzeano decolonial.
\end{abstract}

Palabras clave: Decolonización. Desplazamientos. Enseñanza de la Lengua Española. Eurocentrismo. Racialidad.

\section{INTRODUÇÃO}

\section{PERTENCIMENTO ${ }^{3}$}

Ao iniciar a escrita desse texto, devo por respeito e reconhecimento, pedir licença àqueles que vieram antes de mim. As dores sofridas pelas violências não foram na minha pele, mas foram naqueles que resistiram e permitiram que eu chegasse até aqui. Trago em meu DNA as marcas de uma colonização que trazia nome de progresso, salvacionismo, entre tantos outros argumentos que foram utilizados para transformar o outro em um não-ser.

As tentativas de branqueamento que marcam minha pele denominada parda não ocultaram por muito tempo as minhas raízes que ouvindo repiques de atabaques fizeram com que minha alma reconhecesse o seu lugar. As minhas memórias ancestrais emergiram daquele lugar chamado silenciamento e meu coração pulsando junto às batidas do tambor abriu os meus

\footnotetext{
${ }^{3}$ Este subtítulo é apresentado em primeira pessoa porque foi escrito a partir da experiência direta de Ana Caroline em sala de aula. Lidyane, também professora, compartilha de várias dessas inquietações em seu próprio ofício, mas, este trecho reflete a experiência de Ana Caroline.
} 
olhos para o mundo eurocentralizado que me objetificara. Necessito tirar as sandálias e pisar nessa terra que guarda as lágrimas, o sangue, a separação e a morte. Preciso me defumar para respirar as raízes que reavivam a minha essência. Preciso girar para que no movimento da dança dos meus ancestrais eu me veja como realmente sou.

Assim, em meio a vertigem, repenso o meu papel no mundo e por mais que eu entenda que não estou aqui para repetir padrões salvacionistas, sei que o meu lugar na academia é um lugar também de enegrecimento. É o lugar de re-significar tudo o que aprendi e re-elaborar discursos para que se revelem decolonizados ${ }^{4}$ e decolonizadores. Porque aqueles que eram considerados outros, também são ser.

Repensar o meu lugar no mundo é indagar, questionar, refletir sobre as práticas que exerço enquanto professora de língua espanhola na rede pública estadual de ensino. Esse foi um dos motivos que inquietou - me a escrever esse artigo, pela necessidade de compreender de que maneira podemos colocar em ação as práticas decoloniais dentro do ensino de Língua Estrangeira Espanhola, sendo essa uma área carente de vertentes que se desvinculem do eurocentrismo.

\section{EUROCENTRISMO COLONIAL NO ENSINO DE LÍNGUA ESPANHOLA}

Por muitos anos, o ensino de Língua Espanhola no Brasil foi relegado a segundo plano, mesmo sendo um país cercado por outros países que falam o espanhol e que mantêm relações comerciais com o mercado brasileiro. Somente depois do tratado do Mercosul foi que o idioma hispânico conseguiu espaço um pouco maior dentro dos espaços formais de ensino, fato que se legalizou após a Lei n. 11.161/2005 .

As diretrizes que as escolas devem seguir estão na LDB (Lei de Diretrizes e Bases), nos PCN (Parâmetros Curriculares Nacional), nas OCEM (Orientações Curriculares para o Ensino Médio) e em tantas outras normativas da "educação maior", termo utilizado por Silvio Gallo 6 para falar sobre a educação como uma máquina de poder que "regula" os conteúdos e práticas que acontecem no ambiente escolar, Para Gallo (2003, p. 65), “a educação maior procura

\footnotetext{
${ }^{4}$ Utilizo aqui o termo decolonizados, com base nos conceitos de COSTA e GROSFOGUEL (2016) apresentados no texto Decolonidade e perspectiva negra, para desconstruir a ideia do conhecimento europeu como única verdade e trazer à tona um conhecimento histórico-cultural, outrora fadado à marginalidade, para dentro dos espaços formais de educação.

${ }^{5}$ De acordo com o texto da Lei 11.161 de 5 de agosto de 2005, o ensino de língua espanhola no ensino médio é de oferta obrigatória pelas escolas e matrícula facultativa para os estudantes. Deste texto conclui-se que a língua espanhola entra no currículo escolar como a segunda língua optativa, uma vez que a língua moderna obrigatória será escolhida pela comunidade escolar.

${ }^{6}$ Além do conceito de "educação maior", Gallo também faz um deslocamento do conceito apresentado por Deleuze e Guattari sobre "literatura menor" para uma "educação menor" que se refere a educação feita em sala de aula. Esse conceito será trabalho no decorrer desse artigo.
} 
construir-se como uma imensa máquina de controle, uma máquina de subjetivação, de produção de indivíduos em série" o que nos remete ao efeito de homogeneização da educação.

Esses documentos que regem a educação formal trazem conteúdos e diretrizes eurocentrados, marginalizando toda forma de conhecimento que advém de outros povos. Quando se referem a cultura ou interculturalidade, citam como se fosse algo estático ou folclorizado. Trata-se de um tipo de ensino que não contribui para uma aprendizagem significativa, uma vez que os educandos não se percebem enquanto sujeitos desse processo, sendo consideradas irrelevantes as realidades e os aspectos socioculturais das comunidades onde tais estudantes estão inseridas/os.

Nesse sentido, cabe olhar com atenção para as modificações promovidas na LDB, pelas Leis 10639/2003 e 11645/2008, que preveem o ensino de História e Cultura afro-brasileira e africana nas redes públicas e particulares de educação. Além de ser uma lei que é apresentada como uma conquista de direitos, como se não fosse um dever do Estado proporcionar esses espaços, nos deparamos com a ausência de currículos de formação que priorizem esses saberes na formação de professoras/es. Na maioria das graduações, pouco se conhece sobre a história de povos negros e indígenas a partir de seus próprios olhares e enunciações. Talvez ainda haja dificuldades das instituições e mesmo da comunidade escolar de tratar de tais assuntos, tanto que geralmente são tratados em momentos estanques. As alterações legislativas, portanto, não parecem suficientes para superar certa inércia estrutural e institucional incapaz de reconhecer a plena humanidade do Outro ${ }^{7}$. Como observa Sueli Carneiro:

A negação da plena humanidade do Outro, a sua apropriação em categorias que lhe são estranhas, a demonstração de sua incapacidade inata para o desenvolvimento e aperfeiçoamento humano, a sua destituição da capacidade de produzir cultura e civilização prestam-se a afirmar uma razão racializada, que hegemoniza e naturaliza a superioridade européia. (CARNEIRO, 2005, p. 99)

A reprodução desta negação se dá também através da linguagem. Para Veiga-Neto (2007, p. 91), “dado que cada um de nós nasce num mundo que já é de linguagem, num mundo em que os discursos já estão há muito tempo circulando, nós nos tornamos sujeitos derivados desses discursos." Assim, no Brasil, não se pode negar que a formação dos sujeitos por discursos racializantes contribui para a naturalização de disposições preconceituosas e práticas racistas. Tal racialidade é

\footnotetext{
${ }^{7}$ Segundo Silvio Almeida (2018, p.38 e 39)“O racismo é estrutural. Comportamentos individuais e processos institucionais são derivados de uma sociedade cujo racismo é regra e não exceção. O racismo é parte de um processo social que "ocorre pelas costas dos indivíduos e lhes parece legado pela tradição."
} 
[...] noção relacional que corresponde a uma dimensão social, que emerge da interação de grupos racialmente demarcados sob os quais pesam concepções histórica e culturalmente construídas acerca da diversidade humana. Disso decorre que ser branco e ser negro são consideradas polaridades que encerram, respectivamente, valores culturais, privilégios e prejuízos decorrentes do pertencimento a cada um dos pólos das racialidades. (CARNEIRO, 2005, p. 34)

A reflexão sobre práticas decoloniais dentro do Ensino de Língua Espanhola nas escolas públicas de Ensino Médio no Brasil reconhece essa violência praticada contra os povos que hoje habitam a América, os "Amefricanos". ${ }^{8}$ Apesar de os países da América latina terem deixado de ser colônia, percebemos que o processo colonial se mantém através daqueles que são chamados de aparelhos ideológicos do Estado, dentro os quais podemos destacar a escola. Sabendo que a escola faz parte, segundo Foucault, de uma das instituições de sequestro ${ }^{9}$, podemos refletir sobre o seu papel na objetificação dos corpos para que se tornem docilizados e moldáveis, para que sejam transformados em força de trabalho. Usando como exemplo o estado da Bahia, temos uma educação com o slogan "Educar para transformar". Mas quem eles querem transformar? Ou em quê(m) eles querem transformar?

No que diz respeito ao eurocentrismo que marca o ensino da Língua Espanhola na América latina, é importante recordar a centralidade da imposição do idioma no processo colonizador, com tentativa de aniquilação das histórias, culturas e conhecimentos das populações nativas desse território, assim como dos povos africanos que foram violentamente obrigados a habitar esse continente através da escravização. No Brasil, o ensino da Língua Espanhola nas escolas tinha o espanhol peninsular como língua de prestígio. Ou seja, o idioma ensinado nas escolas dava preferência ao aprendizado da língua falada na Espanha, desmerecendo todos os outros países que, ainda que forçosamente, tenham sido obrigados a “adotar" o idioma do colonizador como língua materna.

No entanto, há que se perceber também as resistências oferecidas por estes mesmos povos. Existem muitas contribuições de africanos e nativos dessas terras que, apesar de excluídas dos espaços formais de saberes, ou incluídas sem o devido reconhecimento de sua origem, continuam resistindo ao tempo e às mais diversas formas de racialismo, mantendo viva as línguas, as memórias, as histórias e as culturas dos povos que os colonizadores quiseram silenciar.

\footnotetext{
${ }^{8}$ Para Lélia Gonzalez, a categoria de Amefricanidade incorpora todo um processo histórico de intensa dinâmica cultural (adaptação, resistência, reinterpretação, e criação de novas formas) que é afrocentrada.

${ }^{9}$ Em Vigiar e punir, por exemplo, são inúmeras as passagens em que ele mostra a identidade entre a prisão, o manicômio, a fábrica, o quartel e a escola, todas elas instituições de sequestro, isso é, instituições capazes de capturar nossos corpos por tempos variáveis e submetê- los a variadas tecnologias de poder. ( VEIGA-NETO, 2007, p.76)
} 
Lélia Gonzalez (1988), em seu texto sobre A categoria político-cultural de Amefricanidade, já nos alertava que na América Latina existe um racismo por denegação ${ }^{10}$ (o racismo disfarçado) e que, nos locais onde existe esse processo de segregação, a força cultural surge como estratégia de resistência. Vemos esse exemplo no Candombe Uruguaio, pois no Uruguai, país de maioria branca, uma das maneiras de se manter viva a memória dos negros é através dessa manifestação cultural.

Todavia, há alguns obstáculos ao desenvolvimento do interesse sobre o aprender e o ensinar um idioma tão latinizado. E não se pode negar o efeito colonial no âmbito educacional. Raramente se encontram dentro das universidades espaços para uma educação que acolha epistemologias não euro centradas. Muitas/os professoras/es assim formadas/os tendem a contribuir para a continuidade dessas ausências nas escolas, reproduzindo esses conhecimentos, tidos como verdade única, sem se preocupar em refletir sobre a inserção de outros saberes na educação.

Se, com Foucault, nos concebemos enquanto sujeitos constituídos pelos discursos que constituem as sociedades em cada época histórica e pelas relações que estabelecemos no mundo, desde a mais tenra infância somos forjados dentro de uma sociedade colonizada que concebe uma ideia de dualidade entre certo e errado, bem e mal, o que é verdadeiro e o que é falso, dispondo as ideias do colonizador como as únicas a serem aceitas e verdadeiras. Como observa Veiga-Neto:

Em vez de ver a linguagem como um instrumento que liga o nosso pensamento à coisa pensada, ou seja, como um instrumento de correspondência e como formalização da arte de pensar, Foucault assume a linguagem como constitutiva do nosso pensamento e, em consequência, do sentido que damos às coisas, à nossa experiência, ao mundo. (2007 p. 89)

Quantas vezes não nos pegamos reproduzindo discursos estabelecidos sem atentar que é através deles que aceitamos ou não as manifestações de um saber? Para Veiga-Neto, os discursos formam sistematicamente os objetos de que falam. Se é assim, não formam e definem também quem pode ser sujeito? Nas palavras de Carneiro:

Então, raça, cor, cultura, religião e etnia seriam da ordem do ôntico, das particularidades do ser. Ser, e especificamente Ser Humano, inscreve-se na dimensão ontológica. $\mathrm{O}$ que nos permite supor que o racismo reduz o ser a sua dimensão ôntica, negando-lhe a condição ontológica, o que lhe atribui incompletude humana. (CARNEIRO, 2003, p.27)

\footnotetext{
${ }^{10}$ Termo que Lélia pega emprestado de Freud para falar de "um processo pelo qual um indivíduo, embora formulando um de seus desejos, pensamentos ou sentimentos, até aí recalcados, continua a defender-se deles ainda que lhe pertença."
} 
Ora, se o negro ou o indígena é visto como o Outro, um não -Ser, é alguém que não pode ser provido de história, cultura, religião, idioma e todo e qualquer outro aspecto que o humanize. Lélia Gonzalez vai usar a palavra infante que não é sujeito do seu próprio discurso, à medida que é falado pelos outros. ${ }^{11}$ É a negação de ser o sujeito do seu próprio discurso, da própria história.

Estes discursos, que ativaram o seu poder reforçando a superioridade do colonizador, também expõem fissuras. Assim, quando a escola se nega a falar o espanhol miscigenado, perguntas emergem entre as/os estudantes, principalmente quando se trata de cultura, variações linguísticas e curiosidades sobre os países hermanos. É dentro do espaço escolar, onde há a negação dos saberes, que, muitas vezes, surge a fala daqueles que eram silenciados.

\section{ROTAS DE DESLOCAMENTOS DELEUZEANAS}

$\mathrm{Na}$ busca por estratégias pedagógicas que nos permitam escapar de uma inércia epistemicida na realidade educacional, são valiosas as reflexões desenvolvidas por Silvio Gallo no livro Deleuze e a Educação. Neste, além de discutir o pensamento de Deleuze e Guatarri, ele faz deslocamentos dos conceitos desses teóricos para o campo educacional.

Segundo Gallo (2003, p. 57), o filósofo da educação deve ser aquele que cria conceitos e que instaura uma plano de imanência que corte os saberes educacionais. Esse Plano de Imanência corresponde à tentativa e ao trabalho de criar conceitos que nos ajudem a enfrentar os problemas que vivenciamos no campo da educação, utilizando o instrumental filosófico que é instaurar, inventar, criar. O campo da educação aqui focado é o da educação menor que segundo o autor é o trabalho feito em salas de aula, uma micropolítica que não segue necessariamente os ritos da educação maior, micropolítica. Observar as microrrevoluções que acontecem nos espaços do cotidiano escolar nos permite repensar as práticas em sala de aula, trazendo novas estratégias que podem ser reestruturadas e usadas em tentativas de aprendizagem.

A noção de Deleuze sobre a multiplicidade permite romper com o que conhecíamos sobre disciplinaridade ligada ao conceito ultrapassado, porém vigente, de árvore do conhecimento que limita e segmenta cada área do saber. A disciplinaridade, assim entendida, é cega ao que acontece na realidade, onde temos múltiplas coisas acontecendo o tempo todo e ao mesmo tempo, onde conhecimentos são produzidos e vão se relacionando, misturando,

11 GONZALEZ, Lélia. A categoria político-cultural de amefricanidade. In: Tempo Brasileiro. Rio de Janeiro, No. 92/93 (jan./jun.). 1988b, p. 69-82. 
miscigenando, como rizoma. O rizoma é feito de conexões, bifurcações e encontros nunca antes imaginados.

Podemos pensar no conceito de rizoma quando analisamos a língua espanhola falada na América latina, pois a miscigenação linguística é tão grande que não temos como mensurar onde começa, onde nos leva, onde termina ou se termina. A riqueza linguística é exuberante e nos leva por caminhos imprecisos. Caso se trabalhe com variações linguísticas, o caminho é longo e tentar correr atrás de etimologias talvez seja uma tarefa inútil. Lélia Gonzalez (1988, p.70) já indicava em seus estudos que, no contato que teve com manifestações culturais negras de outros países, ela pode constatar similaridades nos falares do Brasil e de alguns países que têm como idioma oficial o espanhol. Para ela, o contato que os negros escravizados tiveram nessas regiões modificou o sistema linguístico que foi imposto em cada território do que conhecemos como América Latina. Sendo assim, por quê não nos deixamos emaranhar no rizoma que pode ser o ensino do idioma Espanhol?

Vejamos como algumas características da metáfora do rizoma se conectam com o ensino de Língua Espanhola. Iniciamos com o princípio de Conexão, segundo o qual qualquer ponto de um rizoma pode estar conectado a qualquer outro. Assim, a ação do colonizador obrigando à interação entre os nativos da terra e populações negras escravizadas, de várias etnias, em várias partes do território latino-americano, estabeleceu conexões entre estes mesmos povos. Pelo princípio de Cartografia, observamos que, apesar de poder ser mapeado, o ensino da língua espanhola a partir do contexto do idioma falado nos países latino-americanos, assim como o rizoma, pode ser acessado em qualquer ponto porque ele tem entradas múltiplas, não só pela formação do idioma falado nesses países, mas porque pode remeter a quaisquer outros pontos de seu território.

Igualmente, a Heterogeneidade e a Multiplicidade também se fazem presentes, pois a heterogeneidade está nos falares dos povos latinos americanos, tornando-se uma multiplicidade de saberes, falares e culturas que não podem ser reduzidas à unidade. Pela noção de Ruptura assignificante, que afasta hierarquias, não há como o processo de ensino e aprendizagem do idioma estar ligado tão somente a um sistema linguístico europeizado. Com a noção de Decalcomania, podemos colocar os rizomas sobre as árvores como num decalque, assim podemos colocar o espanhol falado nos países latino-americanos sobre o espanhol peninsular e permitir o surgimento de outras multiplicidades, para que se revelem novos saberes, novas estratégias de ensino e novas significações.

Além da ideia de rizoma, também pode ser útil conhecer o conceito de Literatura Menor, apresentada por Deleuze e Guattari, para refletir sobre a decolonização do ensino de Língua 
Espanhola, uma vez que "Uma literatura menor não é a de uma língua menor, mas antes a que uma minoria faz em uma língua maior.", sendo possível "Subverter uma língua, fazer com que ela seja o veículo de desagregação dela própria" (GALLO, 2003, p. 62). Enquanto que o deslocamento feito por Gallo é para o campo educacional, nosso próprio deslocamento é para, especificamente, o ensino de Língua Espanhola numa perspectiva decolonial.

É interessante em primeiro lugar frisar que a questão da utilização da palavra "menor" não quer representar aqui sentido de inferioridade, mas de questões sociais como quando tratamos a maioria populacional, como negros e pardos, por exemplo, como minoria. Sendo assim, essa língua "maior", a que foi imposta pelos colonizadores, foi subvertida, foi desagregada pela interferência das minorias colonizadas. Dentre as características da literatura menor que Gallo deslocou para a educação menor, está a de desterritorialização. A língua é territorialista e está intrinsecamente ligada à cultura e à tradição local. Ao impor seu idioma, o colonizador que impor também suas regras, tradições, cultura e história. Ao ser desterritorializada, sair do seu território, a língua desestabiliza e cria um novo conjunto de normas e sentidos. A influência das línguas e dialetos dos povos que foram escravizados e colonizados agiram diretamente no idioma imposto pelo colonizador criando, na realidade, um outro idioma, que com certeza não é mais o que lhes foi outorgado.

O caráter tonal e rítmico das línguas africanas trazidas para o novo mundo, além da ausência de certas consoantes (como o L ou o R por exemplo), apontam para um aspecto pouco explorado da influência negra na formação histórico-cultural do continente como um todo (e isto sem falar nos dialetos crioulos do Caribe) (GONZALEZ, 1988, p.70)

A ramificação política é uma outra característica a ser tratada, pois a própria existência de um idioma que sofreu "rasuras" dentro dos vocabulários originais e das regras gramaticais, cedendo espaços para palavras que faziam parte apenas do vocabulário negro ou indígena, principalmente no que diz respeito à língua coloquial, que é a língua usada de fato, é um ato político. É resistência!

Por fim, ao trazer saberes vários para a sala de aula, a inserção do ensino da Língua Espanhola falada na América latina ganha um valor coletivo. Nela serão trabalhados, juntamente aos aspectos linguísticos, aspectos culturais, históricos e sociais que trazem toda a representatividade dos povos que formaram, através de uma miscigenação violenta, a língua e sociedade a que pertencemos hoje.

\section{POR UM DEVIR-DELEUZEANO DECOLONIAL}

Lélia Gonzalez nos convida a uma reflexão importante quando nos indaga: "Quanto a nós, negros, como podemos construir uma consciência efetiva de nós mesmos, enquanto 
descendentes de africanos, se permanecemos prisioneiros, cativos de uma linguagem racista?" Necessitamos refletir sobre quem somos e a partir daí reformular nossos pensamentos e práticas para que se tornem decoloniais.

Podemos repensar as práticas pedagógicas que exercemos em sala de aula, pois há muito o que rever a partir dos erros que cometemos enquanto professora/or. Especialmente quando sabemos que estamos seguindo o caminho que a sociedade de controle nos indica e nada fazemos para modificar a realidade das nossas escolas. Quando reproduzimos práticas racistas e colonialistas estamos excluindo nossas/os estudantes de um processo de pertencimento.

Além do envolvimento no processo de construção das aulas, também temos o dever de saber escolher o material utilizado em sala de aula, sabendo que esse processo é uma construção política que influenciará na formação dos educandos. Se já compreendemos que a ausência dos países latino-americanos hispanohablantes nos livros ou sua folclorização é uma forma de silenciar e invisibilizar esses povos, devemos por consciência e ética trazer à tona esses saberes e reconhecer que o ensino de língua espanhola ainda está no processo colonial.

Segundo Gallo, ser um professor militante é aquele que produz a possibilidade do novo e constrói coletivamente. É se opor à escola como máquina de controle e seguir sendo máquina de resistência. Sabendo que fazer parte de uma militância no campo educacional é lutar por valores coletivos, deixando as individualidades na busca da multiplicidade. É adentrar num campo rizomático, lidando criativamente com a rigidez apresentada pelos documentos que regem a educação.

Nesse texto, as reflexões são chamamentos para que possamos refletir sobre os conceitos a partir de nossas realidades, buscando aproveitar ideias que são transgressoras às práticas que já estão estabelecidas, construindo novos conceitos e novas perspectivas, ainda que tenhamos que correr o risco eminente do enfrentamento com as máquinas de controle e de objetificação dos sujeitos. Resistir à cooptação, resistir a ser incorporado; manter acesa a chama da revolta, manter em dia o orgulho da minoridade, manter-se na miséria e no deserto. Educação menor como máquina de resistência." (GALLO, 2003, p. 70). Que as palavras de Silvio Gallo nos sirvam de incentivo nessa caminhada dentro desse processo de um devir-Deleuzeano.

\section{REFERÊNCIAS}

ALMEIDA, S. O que é racismo estrutural? Justificando/Letramento, 2018. Introdução (p. 1921), Racismo e Ideologia (60-82), Racismo e Política (86-127)

BRASIL. Diretrizes curriculares nacionais para educação das relações étnico-raciais e para o ensino de história e cultura afro-brasileira e africana. Brasília, DF: SECAD, 2004.

BRASIL. Lei $n^{o} 11.161$, de 5 de agosto de 2005. Dispõe sobre o ensino da língua espanhola. Diário Oficial da União, Brasília, DF, 5 ago. 2005. Disponível em: 
https://www2.camara.leg.br/legin/fed/lei/2005/lei-11161-5-agosto-2005-538072publicacaooriginal-31790-pl.html . Acesso em: 25/08/2019.

CARNEIRO, A. S. A Construção do Outro como Não-Ser como fundamento do Ser. Feusp, 2005. (Tese de doutorado)

GALLO, S.. Deleuze \& a Educação. Belo Horizonte: Autêntica Editora, 2003.

GONZALEZ, L. A categoria político-cultural de amefricanidade. In: Tempo Brasileiro. Rio de Janeiro, No. 92/93 (jan./jun.). 1988b, p. 69-82.

VEIGA-NETO, A. Foucault e a Educação. Belo Horizonte: Autêntica Editora, 2007. 